- "Insurmountable Opportunities: Advanced Technology and the Academic Library," by Bill Potter

- "Analysis and Library Management," by Malcolm Getz

Mary Jo Lynch is director of the American Library Associations's Office for Research. Arthur P.
Young is director of the library at the University of South Carolina.

Academic Libraries: Research Perspectives may be ordered for $\$ 27.50$ from ALA Publishing, $50 \mathrm{E}$. Huron St., Chicago, IL 60611. ISBN 0-8389-0532-

3.

\title{
Poster preparation for ALA Annual Conference
}

\section{By Suzanne D. Gyeszly}

Resource Development Librarian

Texas A\&M University
The first poster session was introduced in Philadelphia in 1982 during the American Library Association Annual Conference. Since the beginning, it became very popular among librarians, both for participants as well as observers. The number of applications, participants, subject topics, and observers have increased during the past years. Among the most popular subject categories are: automation, technology, cataloging systems, public awareness, publishing, services to special groups, collection development, serials, special collections, reference and information services, bibliographic instructions and education, management, personnel, and planning. Last year in Dallas 105 posters were exhibited in thirty major subject categories. The purposes of the poster sessions are to:

1. promote research project(s) of an individual librarian or a team.

2. provide an effective communication of ideas and research.

3. present a broad range of topics in an informal way.

4. provide the opportunity for both beginners and experienced librarians to participate in a national conference in a juried session.

5 . place the presenter's institution in a national spotlight.

6. obtain valuable information on innovative programs, in a relatively short time period.

\section{Preparation for a successful poster session}

Based on my personal experiences after participating in several poster sessions since 1982, and currently preparing three posters for the Chicago
Annual Conference, I strongly believe that the hardest task is to complete the first poster. Therefore, the purpose of my article is to provide a "hands-on" experience for all the librarians who are struggling with their current research and poster or planning to participate in a poster session in the future.

\section{Suggested calendar of events}

\section{September to December}

Identify the future research or subject topic(s) for a poster. Subject should be relevant to the researcher's interest or institution. If "seed money" is needed to execute the project, the library director, university, institution administration or outside sources may be approached for funding. If funding is not available, but the researcher still wants to proceed with the project, I believe that it is worthwhile to personally finance the work.

\section{January}

Obtain an official poster's abstract form and instruction manual from the ALA exhibit booth at the ALA Midwinter Meeting or submit a letter for the necessary information from ALA Headquarters in Chicago. Read all instructions before preparing the abstract. Prepare a well-written, short, but very specific abstract about the research project. The abstract should cover major areas: statement of the problem, objectives, methodology, anticipated research results and conclusions. Before the deadline, submit the poster's abstract to the Chair of the ALA Poster Session Committee using the official abstract form. 


\section{February to March}

Collect data for the research. Depending on the research topic, a variety of methodologies can be used for data generation. Some of the most commonly used methods are distributing mail or handout questionnaires for a designated group, observing the use patterns of specific software packages, testing a new CD-ROM product, evaluating reference service, or creating a new bibliographical instructional system. Use the most appropriate tool and method to collect data. If the poster is accepted, you should receive a poster acceptance letter from the chair of the ALA Poster Session Committee by late March. The letter includes the date, time, and designated area of the poster session.

\section{April to May}

Select and analyze the collected data. The commonly available spreadsheets like Lotus 1-2-3 or Quattro could be used for quantitative data analysis. Complete charts, graphs, and tables using popular IBM or MacIntosh software packages such as Harvard Graphics, MacDraw II or SuperPaint. Drawings, photographs (color or black and white) and other items could be used for illustrations.

\section{June}

Prepare the poster. The guidelines and specifications requested by the ALA Poster Sessions Committee must be followed. Each poster should include a copy of the research title, presenter's name and institution, abstract, statement of the problem, objectives of the research, methodology, major findings, and conclusion. A logical sequence of the display should be followed beginning with an introduction, moving through development and to the conclusion. If necessary, number the sheets for an easier and faster display arrangement. Mount information, graphs, photos, etc. on separate poster boards for easy transportation. Furnish some hand-out materials for observers. Graphs, charts, or a summary of the research help passersby quickly grasp the concept you are presenting. Purchase thumbtacks or push pins. Prepare a notebook for visitors' addresses, affiliation and phone numbers (optional). Print your business cards for personal identification (optional).

\section{June 30 to the day of the poster session}

Observe the designated poster area earlier in the day and pick up one or two Poster Session Abstracts published by ALA (optional). Be sure to arrive at least fifteen minutes earlier than the scheduled time. Put up the poster in a logical sequence by following the numbered charts. Wear your name tag. Be prepared for the poster session at least five minutes before the scheduled time as the observers are eagerly waiting to question you regarding the poster. (Remember they have already read the printed abstract). Be friendly and calm as you answer conference attendees' questions during the given ninety minutes. Give out hand-outs, if requested. If some questions can not be answered or if you run out of hand-outs during the poster session, take the requester's name, address, and phone number and get back to him/her after you return from ALA. Take down the posters when your time has expired.

\section{Conclusions}

Participation in a poster session is an excellent opportunity to discuss the research project with interested colleagues and observers. Many times further good ideas can be added to the project based on comments and suggestions. Also it is a good chance to help other colleagues start similar projects in their institutions. Frequently editors of professional journals are visiting the poster sessions, or they are reading the abstracts during or after ALA. If the project is appealing to them, the presenter often will be asked to write an article for the journal. The problem comes when the presenter receives two or three requests from different publishers for the same project. (It happened to me a year ago, and I had a hard time choosing between two prestigious professional journals). For academic librarians, where publications are required for tenure and promotion, it is an honor to be asked by an editor of a well known, refereed journal.

Author's Note: The authorwishes to thank Fay B. Davis for her help in preparing this manuscript.

\section{Academic librarians in the media}

Two academic libraries have won awards in the first annual Librarians in the Media Contest, co-sponsored by American Libraries and the ALA Public Information Office. This new contest recognizes libraries for "consistently obtaining high-quality media coverage about librarians in non-library media."

The Pikes Peak Community College Learning Resource Center, Colorado Springs, won first prize in the magazine entry category. Brevard Community College Library, Cocoa, Florida, won first prize in the television category for a story about a Cocoa Beach librarian who is also a world weightlifting champion. Both libraries will receive $\$ 100$ gift certificates from ALA Graphics. ALA held the contest in observance of The Year of the Librarian (1989). 


\section{announcing \\ The Ultimate Acquisition \\ Management Tool}
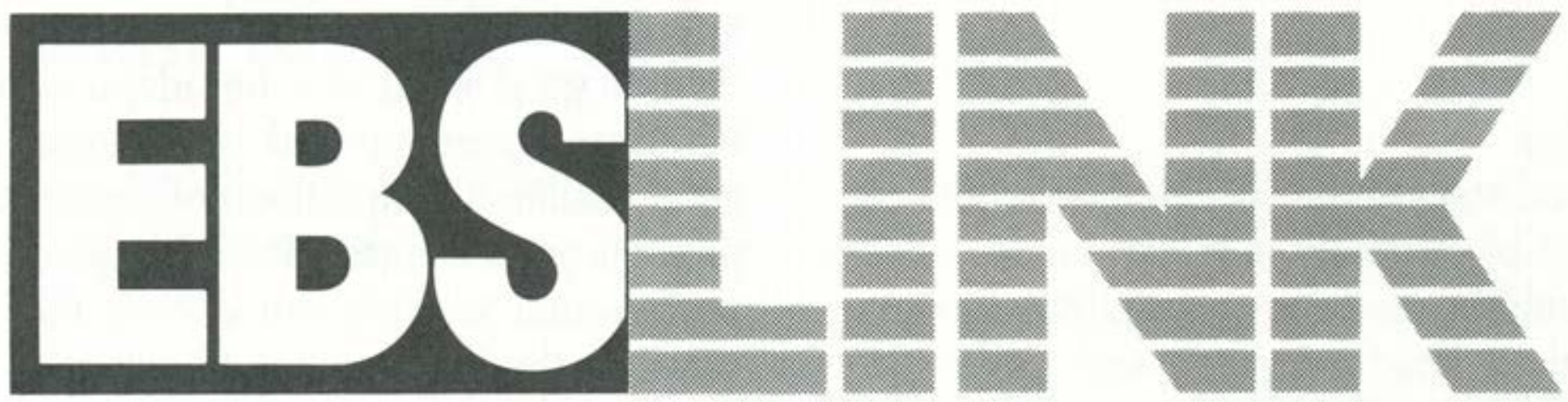

EBS announces a software package designed to serve the professional librarian's needs-NOT THE NEEDS OF YOUR VENDOR. EBS LINK isn't just an ordering device or a list of your vendor's inventory; EBS LINK is a management tool that will HELP YOU THROUGHOUT the acquisitions process.

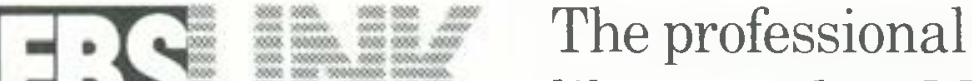

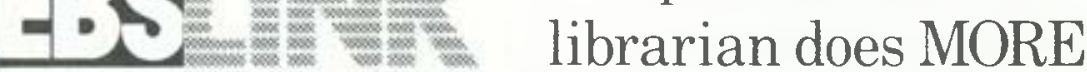

than order books. We realize that and we created EBS LINK to be an ACQUISITIONS MANAGEMENT TOOL. It keeps track of all your budgets, retrieves information the way you should have it, and helps you to be a more efficient librarian.

Every library can use an extra arm or two in its acquisitions department. EBS LINK can help you make EBS your extra arm.

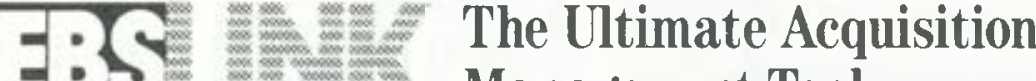

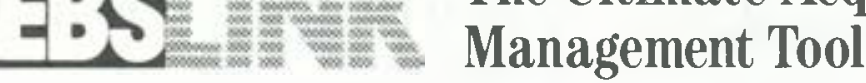

For information about obtaining EBS LINK at no charge, call:

\section{1-800-899-0290}

or write:

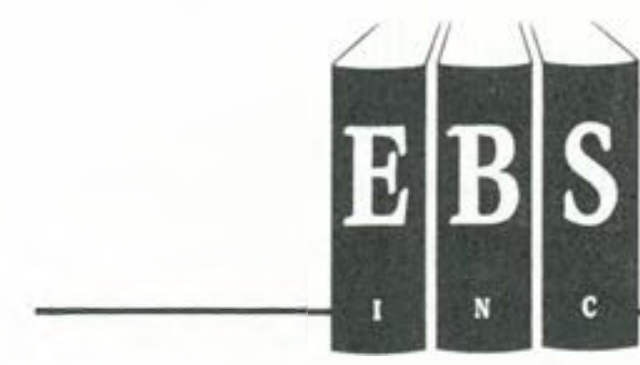

